\title{
CHALLENGES IN OPERATIONS AND MAINTENANCE OF ANTARCTICA GROUND STATION FOR EARTH OBSERVATION SATELLITES
}

\author{
N. Mangala Mani ${ }^{1, *}$, Satyesh Ghetiya ${ }^{1}$, B. Srikanth ${ }^{1}$, C.S Padmavthi ${ }^{1}$, G. Uma Devi ${ }^{1}$, Y.V.N Krishna Murthy ${ }^{2}$ \\ ${ }^{1}$ National Remote Sensing Center, India - (mani_n, satyeshghetiya_g, srikanth_b, padmavathy_cs, umadevi_g)@nrsc.gov.in \\ ${ }^{2}$ Indian Institute of Space Science Technology, Kerala, India - yvnkrishna@gmail.com
}

Commission V, SS: Natural Resources Management

KEY WORDS: Data Reception system (DRS), Data Communication System (DCS), Payload (PLD), Telemetry and TeleCommand (TTC), Visible Orbits.

\begin{abstract}
:
Remote sensing and Geographical Information System (GIS) through Earth Observation (EO) Satellites have become most important tools for many of the societal applications of day-to-day life, during the past few decades of the $21^{\text {st }}$ century, and this need is rapidly increasing. Presently, EO payload (PLD) data from Polar Orbiting Indian Remote Sensing (IRS) Satellite Missions is received at the Integrated Multi-mission Ground segment for Earth Observation Satellites (IMGEOS) at NRSC, Hyderabad, India. But at this geographical location, only four out of fourteen orbits data can be acquired from each of the polar satellites. These polar satellite orbits converge at poles, hence establishing a ground station at Polar Regions has an advantage of acquiring data from ten to twelve orbits.
\end{abstract}

To increase the capability, a data reception Ground Station and Communication facility was established by ISRO at Bharati Station, Antarctica, located at $69^{\circ}$ South and $76^{\circ}$ East, in 2012-2013 (Austral Summer). This station is maintained for flawless operations and smooth flow of IRS Satellites EO data from Antarctica, by three Scientists/Engineers from ISRO, who overwinter at Antarctica, along with other Expedition members, by clearing the pre-requisites for an Antarctica Expedition. While this location is suitable to establish a Ground Station, the local conditions are a challenge to be faced (when established then, and now) to operate and maintain it $24 \times 7$ throughout the year.

On an average, sixty five passes of twelve IRS Satellites are supported for PLD and Telemetry and Tele-Commanding (TTC) activities from this Antarctic Ground station for Earth Observation Satellites (AGEOS).

\section{INTRODUCTION}

Antarctica Ground Station for Earth Observation Satellites (AGEOS) at Bharati Station, Larsemann Hills, East Antarctica, located at $69^{\circ} \mathrm{S}$ latitude $76^{\circ} \mathrm{E}$ longitude, plays a crucial role in supporting the Payload Data (PLD), Real time Telemetry (TM) and Tele-Commanding (TC), together called as TTC, of all Polar Orbiting Indian Remote Sensing (IRS) satellites. Geographical Location of AGEOS is such that a pass is visible in about 25minutes after its visibility at the Integrated Multi-mission Ground segment for Earth Observation Satellites (IMGEOS) Ground station located at $17^{\circ} \mathrm{N}$ latitude and $77^{\circ} \mathrm{E}$ longitude at Hyderabad, India. Figure 1 shows the relative locations of IMGEOS and AGEOS on Google Map (Google Maps, 2018). Of the 14 orbits per day of any IRS Polar Satellite Mission, only four orbits are visible in India (tropical region), while ten to twelve Orbits at Antarctica (polar region) are visible (Modiri et al 2008).

\footnotetext{
* Corresponding author
}

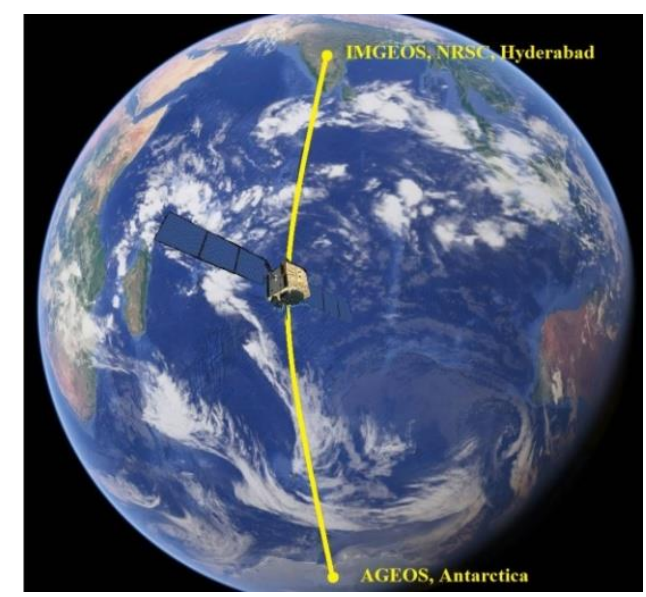

Figure 1. IMGEOS and AGEOS locations (North pole tilted back to show Antarctica for clarity) 
The ground station is presently connected to NRSC, through Intelsat Communication Satellite link. It enables transfer of Pay Load data in near-real-time, and two-way real-time communication for Telemetry and Tele Commanding (Jain 2013) as illustrated in Figure 2. All the Systems are powered by Station's Uninterrupted Power Supply (UPS) and a Backup UPS, for smooth and continuous operations.

\section{Antarctica Ground station - Data reception and transfer}

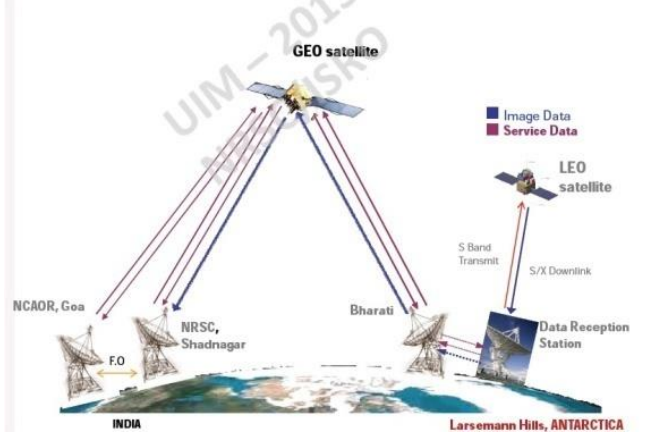

Figure 2. IMGEOS and AGEOS Communication link

It is manned by three dedicated and capable Engineers/Scientists from NRSC, who are part of Indian Scientific Expedition to Antarctica (ISEA) for Operations and Maintenance, throughout the year, working round the clock (AGEOS article).

\section{CHALLENGES AT AGEOS}

Members of Indian Antarctica Expedition are selected by National Centre for Antarctic and Ocean Research (NCAOR website) and prepared to handle the challenges (Bothale et al 2018). The first three authors of this paper were the team members of 36ISEA from November 2016 to December 2017 and the challenges in the following three areas are discussed.

\subsection{Physical and Psychological Challenges}

All the short term (Austral Summer) and long term (winterover) members are screened for medical fitness and compatibility for inter-personal relationships. Apart from this, long term members are screened for psychological fitness.

Staying in isolation away from families and confined to a small group and limited living space for a year is a situation to be faced by every member. Living space is limited to about $50 \mathrm{~m} \times 30 \mathrm{~m} \times 12 \mathrm{~m}(\mathrm{LxBxH})$ space.

During the period of Polar nights/days, there is no sun rise/set for about 49 days. We had to deal with disturbed sleep cycles due to lack of natural sunlight in winter and the presence of continuous daylight in summer (Arendt 2012).
Our daily activities include ground station support in eighthour shifts apart from extra/emergency support during Launch of Missions and station housekeeping support. Involving ourselves in extracurricular activities become essential to overcome this monotonous life.

\subsection{Challenges of Weather}

Climate at Antarctica (Ford 2018) being harsh, all the systems have to withstand heavy winds (of up to 90 knots), snow and subzero temperatures (of minus $45^{\circ} \mathrm{C}$ ). Station is isolated from main land and movements are restricted in winter (March to November) because of the weather. During this period, in case of emergency, no systems or spares or assistance is available and we have to manage with the available resources.

Regular preventive maintenance and corrective maintenance whenever needed, is handled cautiously, braving the weather outside. Snow storms, Blizzards and Chilling temperatures make it hard to be outside for more than two to three hours continuously for any maintenance works.

In the third week of July 2017, while the preparations are being made for station readiness for launch support, part of the cable trench cover, which was blown away due to heavy and long Blizzard, had to be retrieved and fixed, braving the Wind Chill of $-35{ }^{\circ} \mathrm{C}$ and winds of more than 20 knots. Later, a Global Positioning System (GPS) receiver antenna was dislodged due to heavy Blizzard as shown in Figure 3. This is an important component for proper operations, on which the Station timing systems rely and was fixed.

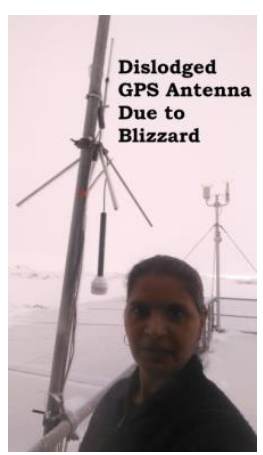

Figure 3. Dislodged GPS antenna

\subsection{Technical Challenges}

To maintain availability of ground station support continuously, all systems (except Antenna) are on hotstandby, few of the systems in cold standby and some systems are as spares. We had to address some of the issues related to software, network, communication link and system replacements for effective support. One GPS receiver and two UPS banks were replaced without interrupting station support. Some of the technical complex 
issues had to be resolved in consultation with the domain and mission experts in the main land through audio and video conferencing mode.

The ground station has Data Reception Systems (DRS), Data Communication Systems (DCS), Network and Timing Systems and UPS systems for PLD and TTC activities. Figure 4 shows the systems inside the control room and outside the station.

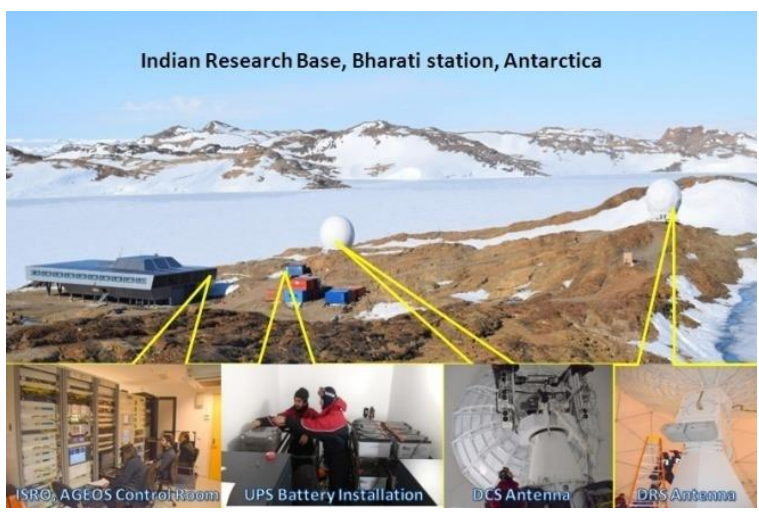

Figure 4. Systems at AGEOS

AGEOS is an important station during the Launch and Early Phase Operations (LEPO) for any Mission. The critical parameters are monitored in real time during the Telemetry reception. Uplinking support is provided for Tele Commanding by ensuring proper communication link for error-free transmission between AGEOS and Mission Operations Complex in India. Three weeks of simulation exercises consisting of Autonomous Checks (AC), Data Flow Checks (DFC) and Total Network Simulation (TNS) checks are carried out apart from regular scheduled day-today activities. Three Launches were supported during our expedition.

The advantage of more number of visible orbits is coupled with the possibility of Clash and Interference from other satellites, demanding complete Attention and Alertness. While systems are robust, working inside and outside the station for smooth operational support demands dedication for work and problem solving capabilities of members.

\section{CONCLUSIONS}

To supply a better quality EO Satellite data with precise and more information content, the number of bands and quantization levels are increased, which in turn leads to increase in data volumes. For this data to be processed and supplied to the user in near real time, it has to be dumped at faster rates. To gain this capability, ground station at AGEOS is established.

During our expedition, with one Data Receiving Antenna, we supported twelve IRS Missions for TTC and seven IRS Missions for Payload data, totaling sixty five pass supports per day on an average. These figures are on the rise with more Missions to be supported.

\section{ACKNOWLEDGEMENTS}

The Authors acknowledge the support of our colleagues and guidance from the respective Section Heads, Group Heads and Group Directors and Deputy Directors. The authors are also grateful to Director NRSC for permitting and encouraging us to submit this work.

\section{REFERENCES}

A. Modiri and L. Mohammady, "Mathematical Prediction of Sun-Synchronous Polar LEO Satellite Visions for Earth Stations," 2008 10th International Conference on Advanced Communication Technology, Gangwon-Do, 2008, pp. 1559-1563.

doi: 10.1109/ICACT.2008.4494077

Antarctic Ground station for Earth Observation Satellites (AGEOS) https://www.isro.gov.in/antarctica-groundstation-earth-observation-satellites-ageos. Retrieved on 20 September 2018

Arendt, J. (2012). Biological Rhythms During Residence in Polar Regions. Chronobiology International, 29(4), 379394. http://doi.org/10.3109/07420528.2012.668997

Arthur B. Ford (2018), Antarctica, In Encyclopædia Britannica online. Retrieved on 20 September 2018 from https://www.britannica.com/place/Antarctica/Climate

Jain, D.S 2013. Advancements in outreach \& updates on ISRO Ground Station. In User Interaction Meet 2013. https://nrsc.gov.in/sites/all/pdf/jai.pdf

Google Maps. 2018. Retrieved from

https://www.google.com/maps/@$21.3768638,86.2798163,14321827 \mathrm{a}, 46 \mathrm{y}, 357.21 \mathrm{~h} /$ data $=! 3 \mathrm{~m}$ $1 ! 1 \mathrm{e} 3$

NCAOR. http://www.ncaor.gov.in/ Retrieved on 20 September 2018

Rajashree V Bothale, Mangala Mani, Padmavathy Chandrasekharan, Kiral Ghodadra, Purvee Joshi, Megha Maheshwari, Deepika Roy, Lakshmipriya Prusty and Ankitha Reddy (2018), Antarctica expedition and role of Indian Women Space Scienceists, ISG Newsletter. Vol. 23, No. 2-4 \& Vol. 24, No. 1 \& 2; June,2018 